CLINICAL STUDY

\title{
Variations in the uncoupling protein- 3 gene are associated with specific obesity phenotypes
}

\author{
Annet F M van Abeelen ${ }^{1,2}$, Mariken de Krom ${ }^{2}$, Judith Hendriks ${ }^{2}$, Diederick E Grobbee ${ }^{1}$, Roger A H Adan ${ }^{2}$ \\ and Yvonne T van der Schouw ${ }^{1}$ \\ ${ }_{1}^{1}$ Julius Center for Health Sciences and Primary Care, University Medical Center Utrecht, Room STR 6.131, PO Box 85500, 3508 GA Utrecht. \\ The Netherlands and ${ }^{2}$ Department of Neuroscience and Pharmacology, Rudolf Magnus Institute of Neuroscience, University Medical Center Utrecht, \\ Universiteitsweg 100, 3585 CG Utrecht, The Netherlands \\ (Correspondence should be addressed to Y T van der Schouw; Email: y.t.vanderschouw@umcutrecht.nl)
}

\begin{abstract}
Objective: Uncoupling protein 3 (UCP-3) uncouples oxidative metabolism from ATP synthesis, resulting in the production of heat instead of energy storage. Single nucleotide polymorphisms (SNPs) in UCP-3 might result in a reduced function or expression of UCP-3 and therefore lead to an increased capacity to store energy as fat.

Design: We conducted a population-based, cross-sectional single-center study among 400 Dutch men between 40 and 80 years.

Methods: Seven SNPs in the UCP-3 gene were genotyped by means of an allele-specific real-time TaqMan PCR. Linear regression analyses were performed to examine the independent effects of these SNPs on obesity phenotypes.

Results: We found a significant association between homozygosity for the minor allele of rs647126, rs1685356, and rs2075577 and an increase in body mass index (BMI; $P=0.033, P=0.016$, and $P=0.019$ respectively). Heterozygosity for rs1685354 was associated with a significant decrease in visceral fat mass $(P=0.030)$.

Conclusions: Our results suggest that genetic variations in the UCP-3 gene are associated with an increase in BMI. A plausible mechanism by which these SNPs lead to an increase in BMI is that due to these SNPs, the UCP-3 activity might be decreased. As a result, uncoupling activity may also decrease, which will lead to an increase in body weight and BMI.
\end{abstract}

European Journal of Endocrinology 158 669-676

\section{Introduction}

Obesity is an increasing health problem in modern societies and a major risk factor for chronic diseases including type 2 diabetes, hypertension, and cardiovascular disease $(1,2)$. It is a multifactorial disease caused by the interaction of genetic, environmental, and psychosocial factors that act through the physiological mediators of energy intake and expenditure (1). An imbalance between this intake and expenditure of energy results in changes in body weight $(3,4)$.

Energy expenditure is a complex trait comprising the basal or metabolic rate at rest, energy expenditure due to physical activity, and diet-induced and adaptive thermogenesis $(3,5)$. Uncoupling proteins (UCPs), a family of mitochondrial transporters, play a significant role in the process of adaptive thermogenesis $(6,7)$. These transporters are known to uncouple oxidative metabolism from ATP synthesis by promoting proton leakage across the inner mitochondrial membrane, resulting in the production of heat instead of energy storage (6-9). As a result of this process of uncoupling, mobilization of triglyceride stocks is induced (8).

UCP-1, the first identified UCP, is a brown adipocytespecific protein. However, in humans, the site of adaptive thermogenesis is probably not restricted to brown adipose tissue, because adults do not have large deposits of brown adipose tissue (6). Rather, skeletal muscle is found to be the most important tissue for adaptive thermogenesis in adult humans $(10,11)$. In 1997, two UCP-1 homologs were identified, UCP-2 and UCP-3. UCP-2 is widely expressed in human tissues, such as the spleen, thymus, leukocytes, macrophage, bone marrow, and stomach $(12,13)$. On the contrary, UCP-3 is highly specific for skeletal muscle and has been suggested to affect the process of adaptive thermogenesis in humans $(12,14)$. However, direct evidence for such a role is lacking, but UCP-3 is somehow involved in fatty acid translocation (15). Reduction in the function or expression of UCP-3 might result in decreased energy expenditure and an increased capacity to store energy as fat (16). Thus, UCP-3 is considered to 
be a candidate gene in the development and maintenance of obesity.

The association between the UCP-3 gene and obesity is under intensive investigation. Most studies regarding the association of UCP-3 with obesity phenotypes focused on individual single nucleotide polymorphisms (SNPs). A number of different amino acid substitutions have been reported, but most of them are rare (17). A relatively common and extensively studied SNP with regard to obesity phenotypes is the rs1800849 SNP within the promoter region, discovered by Schrauwen et al. (18). However, the results of the different studies on this SNP are conflicting (18-28); some studies found a negative association between the T-allele and the body mass index (BMI) in Caucasians (18, 25, 27), while others found a positive (28) or no association $(22,23,26)$.

The aim of this study was to examine the association of common genetic variations in the UCP-3 gene with obesity phenotypes. The association of seven common SNPs with anthropometric parameters was investigated among 400 healthy Dutch male subjects.

\section{Subjects and methods}

\section{Subjects}

We conducted a population-based cross-sectional, single-center study among 400 men aged between 40 and 80 years and living independently. Among this total of 400 male subjects, 382 males were genotyped and analyzed. Two male subjects could not be genotyped due to failure of DNA isolation. Another 16 males were not of Caucasian ancestry and were therefore excluded from analysis.

The subjects and methods of recruitment have been described elsewhere (29). All participants gave written informed consent before enrolment in the study, and the study was approved by the institutional review board of the University Medical Center Utrecht. Data were collected between March 2001 and April 2002

\section{Anthropometric measurements}

Height and weight were measured in standing position without shoes. BMI was calculated as the weight in kilograms divided by the square of the height in meters. Weight circumference was measured at the level midway between the lower rib margin and the iliac crest with participants in standing position without heavy outer garments and with emptied pockets, breathing out gently, and the hip circumference was measured at the level of the greater trochanter. The average of two readings was used in the analyses. Waist-to-hip ratio, which represents a measure of upper body adiposity, was calculated from these two measurements.
Total and trunk lean body mass and fat mass were measured using dual-energy X-ray absorptiometry (Hologic ZDR 1000 densitometer (Hologic, Waltham, MA, USA)).

Visceral and intra-abdominal fat were assessed using ultrasound measurement $(30,31)$. Ultrasonography was performed with an HDI 3000 ultrasound system (Philips Medical Systems, Eindhoven, The Netherlands) using a C4-2 transducer. The distances between the posterior edge of the abdominal muscles and the lumbar spine or psoas muscles are measured using electronic calipers. For all images, the transducer is placed on a straight line drawn between the left and right midpoint of the lower rib and the iliac crest. Distances are measured from three different angles: medial, left, and right for intra-abdominal fat mass and medial for s.c. fat mass in threefold. Measurements are made at the end of quiet expiration, applying minimal pressure without displacement of intra-abdominal contents as observed by ultrasound image. Visceral fat was measured as the distance between the skin and the linea alba and intra-abdominal fat as the distance between the peritoneum and the lumbar spine.

\section{SNP selection and analysis}

The UCP-3 gene spans $8.5 \mathrm{~kb}$ and is located on the distal segment of chromosome 11q13, adjacent to UCP-2 (32). Using the Human Haplotype Map project (HapMap), SNP genotype data were obtained in the coding sequence and $0.85 \mathrm{~kb}$ up- and down-stream of the UCP-3 gene. The obtained genotype data can then be uploaded in the haploview analysis program. Within haploview, an output of all tagging SNPs present in the uploaded genotype data of the UCP-3 gene is produced. For this study, SNPs designated as haplotype-tagging SNPs in the haploview analysis with $r^{2}>0.80$ were selected. The selection of the SNPs was done in March 2007, only the SNPs available at that time were used in the study (33). This resulted in seven SNPs for UCP-3, all of which were haplotype based (rs7930460, rs647126, rs1685356, rs2632723, rs1685354, rs2075577, and rs1800849). All SNPs had a minor allele frequency of at least 10\%. Further description and localization of the selected SNPs is shown in Table 1 and Fig. 1. Linkage disequilibrium (LD) coefficients, $D^{\prime}$ and $r^{2}$, between the SNPs are described in Table 2 .

The SNPs were genotyped by means of an allele-specific real-time TaqMan PCR (34). In summary, two probes are used of which one is specific for the wild-type allele and the other is complementary to the minor allele. By means of two fluorescent reporter dyes (VIC or FAM), which are coupled to the probes, a distinction can be made between the two alleles. When the probe is intact, the fluorescence signal is reduced by the proximity of the quencher to the reporter dye, whereas hybridizing of the fluorogenic probe to the target sequence results in cleavage by AmpliTaq Gold DNA polymerase. Due to this cleavage, the reporter dye is released and the consequent increased fluorescence 
Table 1 Description and localization of selected single nucleotide polymorphisms in the uncoupling protein 3 (UCP-3) gene.

\begin{tabular}{lllllll}
\hline \multirow{2}{*}{$\begin{array}{l}\text { Nucleotide position } \\
\text { on chromosome }\end{array}$} & Position & Amino acid change & Minor allele frequency & HWE & rs\# \\
\hline UCP-3 & 3942914 & Promoter & & 0.26 & 0.280 & rs1800849 \\
& 3938291 & Exon 5 & Tyr210Tyr & 0.42 & 0.789 & rs2075577 \\
& 3936340 & Intron 6 & & 0.24 & 0.146 & rs1685354 \\
& 3935878 & Intron 6 & & 0.21 & 0.086 & rs2632723 \\
& 3935608 & Intron 6 & 0.44 & 1.000 & rs1685356 \\
& 3934769 & Exon 7 & 0.45 & 0.594 & rs647126 \\
& 3933635 & 3' near gene & 0.27 & 0.025 & rs7930460 \\
\hline
\end{tabular}

indicates that the specific probe target has been amplified. This intensity of fluorescence increases in relation to the accumulation of the PCR product.

The primers and probes used in this study were designed by Applied Biosystems (Applied Biosystems, Foster, CA, USA). The reactions were conducted in a 384-well format in a total $4 \mu \mathrm{l}$ reaction volume. Each mixture consisted of $1 \mathrm{l}(8 \mathrm{ng})$ genomic DNA, $0.125 \mu \mathrm{l}$ 40* assay mix (Applied Biosystems), and $2.5 \mu \mathrm{l}$ TaqMan Universal Master Mix (Applied Biosystems). The plates were positioned in an ABI Prism 7900HT instrument in which the amplification protocol consisted of $95^{\circ} \mathrm{C}$ for $10 \mathrm{~min}, 95^{\circ} \mathrm{C}$ for $15 \mathrm{~s}$, and $60^{\circ} \mathrm{C}$ for $1 \mathrm{~min}$ for 60 cycles. The fluorescence intensities were read for each of the wells and the resulting data files from each plate were analyzed with the automated allele-calling software, Sequence Detection System (SDS 2.3, Applied Biosystems, Foster, CA, USA). Finally, the SDS software produces scatter diagrams of the polymorphisms.

\section{Statistical analysis}

The SNPs were tested for deviations from HardyWeinberg equilibrium by means of $\chi^{2}$ tests using a HW-P value cutoff of 0.01 . General and biochemical characteristics of the study population were presented as means \pm s.D. Genotype and allelic distributions were shown by means of the absolute number and their frequency. To examine the independent effects of the genetic SNPs on obesity phenotypes, linear regression analyses were performed. The various genotypes were each represented by two dummy variables that were forced into the model simultaneously. A two-sided $P$ value of 0.05 or less was considered to be statistically significant. All statistical analyses were conducted using SPSS version 14.0 (SPSS, Chicago, IL, USA).

\section{Results}

General characteristics of the subjects are presented in Table 3. The average age of the participants was 60 years. Furthermore, the average BMI was $26.3 \mathrm{~kg} / \mathrm{m}^{2}$ and the mean total fat mass was $17.2 \mathrm{~kg}$, which means that $20.6 \%$ of the total body mass consisted of fat.

The frequencies of the genotypes and alleles of the UCP-3 SNPs are shown in Table 4. On average 98.5\% were successfully genotyped. No significant deviation from the Hardy-Weinberg equilibrium was found for any of the seven SNPs $(P>0.01)$.

\section{Obesity-related phenotypes}

Results of linear regression analysis of obesity-related phenotypes with the seven SNPs in the UCP-3 gene are shown in Table 5. A significant association with BMI was found for three SNPs: rs647126, rs1685356, and rs2075577. Subjects homozygous for the minor allele of rs 647126 had an average increase in BMI of $1.11 \mathrm{~kg} / \mathrm{m}^{2}$ (95\% CI: $0.09 ; 2.14, P=0.033)$. The same tendency was seen for the other two SNPs (rs1685356 and rs2075577). Subjects homozygous for the minor allele of rs 1685356 as well as for rs 2075577 had a significantly increased BMI $\left(1.22 \mathrm{~kg} / \mathrm{m}^{2}, 95 \% \mathrm{CI}: 0.23 ; 2.22\right.$, $P=0.016$ and $1.23 \mathrm{~kg} / \mathrm{m}^{2}, 95 \%$ CI: $0.20 ; 2.25$, $P=0.019$ respectively).

Furthermore, a significant association between rs1685354 and visceral fat mass was observed. A significant decrease in visceral fat mass was seen in subjects heterozygous for this SNP $(-0.52 \mathrm{~cm}, 95 \% \mathrm{CI}$ : $-0.99 ;-0.05, P=0.030)$. Subjects homozygous for the minor allele also had a decreased visceral fat mass, but this did not reach statistical significance $(-0.51 \mathrm{~cm}$, 95\% CI: $-1.61 ; 0.60, P=0.368)$. However, analysis of

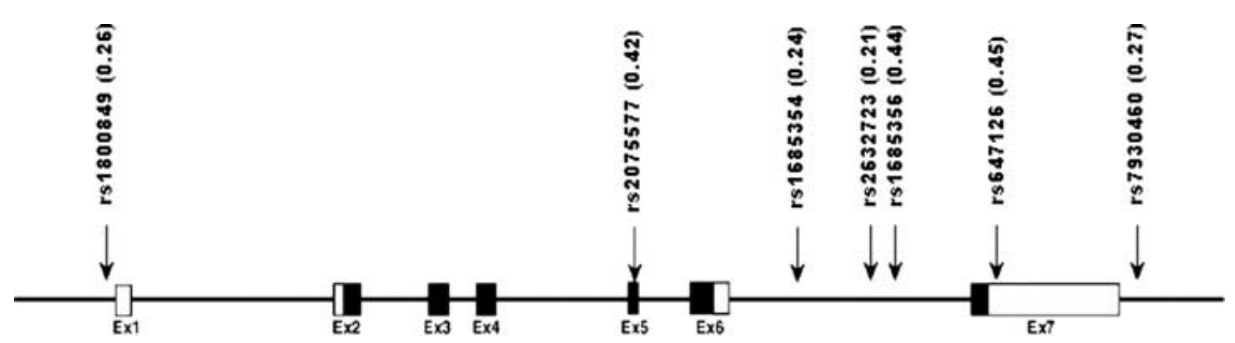

Figure 1 Gene map of the selected single nucleotide polymorphisms in the UCP-3 gene. 
Table 2 Linkage among selected uncoupling protein 3 (UCP-3) single nucleotide polymorphisms.

\begin{tabular}{|c|c|c|c|c|c|c|c|}
\hline & \multicolumn{7}{|c|}{$\left|\boldsymbol{D}^{\prime}\right|$} \\
\hline & rs7930460 & rs647126 & rs1685356 & rs2632723 & rs1685354 & rs2075577 & rs1800849 \\
\hline \multicolumn{8}{|l|}{$r^{2}$} \\
\hline rs7930460 & - & 1 & 1 & 1 & 1 & 1 & 0.945 \\
\hline rs647126 & 0.255 & - & 1 & 1 & 1 & 1 & 1 \\
\hline rs1685356 & 0.236 & 0.900 & - & 1 & 1 & 0.886 & 0.894 \\
\hline rs2632723 & 0.074 & 0.249 & 0.220 & - & 1 & 1 & 1 \\
\hline rs1685354 & 0.092 & 0.337 & 0.286 & 0.814 & - & 1 & 1 \\
\hline rs2075577 & 0.223 & 0.871 & 0.756 & 0.225 & 0.296 & - & 1 \\
\hline rs1800849 & 0.804 & 0.229 & 0.169 & 0.067 & 0.083 & 0.201 & - \\
\hline
\end{tabular}

Table 3 Descriptive characteristics of the 382 Dutch male study subjects.

\begin{tabular}{lc}
\hline Characteristic & Mean \pm s.D. \\
\hline Age (years) & $60.40 \pm 11.22$ \\
Height $(\mathrm{cm})$ & $178.30 \pm 7.15$ \\
Weight $(\mathrm{kg})$ & $83.56 \pm 12.10$ \\
BMl $\left(\mathrm{kg} / \mathrm{m}^{2}\right)$ & $26.27 \pm 3.44$ \\
Waist-to-hip ratio & $0.97 \pm 0.06$ \\
Fat percent & $20.62 \pm 4.19$ \\
Total fat mass $(\mathrm{kg})$ & $17.15 \pm 5.51$ \\
Visceral fat mass $(\mathrm{cm})$ & $7.53 \pm 2.24$ \\
Subcutaneous fat mass $(\mathrm{cm})$ & $2.65 \pm 0.85$ \\
\hline
\end{tabular}

the association between rs1685354 and visceral fat mass in a dominant model showed a statistically significant effect for the combination of heterozygosity and homozygosity for the minor allele $(-0.52 \mathrm{~cm}, 95 \%$ CI: $-0.97 ;-0.07, P=0.025)$.

\section{Discussion}

In this study, we investigated the effect of SNPs in the UCP-3 gene on obesity-related phenotypes among healthy Dutch male subjects. The findings show a significant association between the minor allele of three SNPs (rs647126, rs1685356, and rs2075577) in the
UCP-3 gene and BMI. Furthermore, heterozygosity for rs1685354 was significantly associated with a decrease in visceral fat mass. Analysis of this association in a dominant model showed a statistically significant effect; the presence of the minor allele of this SNP results in a decrease in visceral fat mass of about $0.52 \mathrm{~cm}$. The fact that we did not observe statistical significance for homozygotes for the minor allele is probably due to the small number of subjects $(n=17)$.

We could demonstrate only statistically significant associations between these SNPs and BMI, and not with other obesity phenotypes, such as waist circumference, waist-to-hip ratio, and visceral fat mass. However, for some of the SNPs, trends were suggestive. The association between homozygosity for the minor allele of rs647126 and an increase in BMI is supported by a borderline significant increase in waist-to-hip ratio. Furthermore, homozygosity for the minor allele of rs2075577 is borderline significantly associated with an increase in visceral fat mass.

The amount of visceral fat was assessed using ultrasonography, but the gold standard for this measurement is computer tomography (CT). However, the feasibility of use of CT in large epidemiological studies is very limited, because of the necessary equipment, costs, and radiation exposure. Moreover, a validation study on the assessment of visceral fat by means of abdominal

Table 4 Genotype and allelic distributions of single nucleotide polymorphisms in the uncoupling protein 3 (UCP-3) gene among healthy Dutch male subjects.

\begin{tabular}{|c|c|c|c|c|c|}
\hline \multirow[t]{2}{*}{ SNP } & \multicolumn{3}{|c|}{ n (\%) Genotypes } & \multicolumn{2}{|c|}{$n(\%)$ Alleles } \\
\hline & AA & $A G$ & $\mathrm{GG}$ & A & $\mathrm{G}$ \\
\hline rs7930460 & $\begin{array}{l}194(51.1) \\
\mathrm{GG}\end{array}$ & $\begin{array}{l}167(43.9) \\
\mathrm{GA}\end{array}$ & $\begin{array}{l}19(5.0) \\
\mathrm{AA}\end{array}$ & $\begin{array}{l}555(73.0) \\
G\end{array}$ & $\begin{array}{l}205(27.0) \\
\text { A }\end{array}$ \\
\hline rs647126 & $\begin{array}{l}108(29.3) \\
G G\end{array}$ & $\begin{array}{l}188(50.9) \\
\mathrm{GA}\end{array}$ & $\begin{array}{l}73(19.8) \\
A A\end{array}$ & $\begin{array}{l}404(54.7) \\
G\end{array}$ & $\begin{array}{l}334(45.3) \\
\text { A }\end{array}$ \\
\hline rs1685356 & $\begin{array}{l}119(31.4) \\
\mathrm{AA}\end{array}$ & $\begin{array}{l}185(48.8) \\
A G\end{array}$ & $\begin{array}{l}75(19.8) \\
G G\end{array}$ & $\begin{array}{l}423(55.8) \\
A\end{array}$ & $\begin{array}{l}335(44.2) \\
G\end{array}$ \\
\hline rs2632723 & $\begin{array}{l}235(62.5) \\
\text { TT }\end{array}$ & $\begin{array}{l}126(33.5) \\
\text { TC }\end{array}$ & $\begin{array}{l}15(4.0) \\
\mathrm{CC}\end{array}$ & $\begin{array}{l}596(79.3) \\
T\end{array}$ & $\begin{array}{l}156(20.7) \\
C\end{array}$ \\
\hline rs1685354 & $\begin{array}{l}211(55.8) \\
\text { TT }\end{array}$ & $\begin{array}{l}150(39.7) \\
\mathrm{TC}\end{array}$ & $\begin{array}{l}17(4.5) \\
\mathrm{CC}\end{array}$ & $\begin{array}{l}572(75.7) \\
T\end{array}$ & $\begin{array}{l}184(24.3) \\
\mathrm{C}\end{array}$ \\
\hline rs2075577 & $\begin{array}{l}125(33.1) \\
\mathrm{CC}\end{array}$ & $\begin{array}{l}187(49.5) \\
\text { CT }\end{array}$ & $\begin{array}{l}66 \text { (17.5) } \\
\text { TT }\end{array}$ & $\begin{array}{l}437(57.8) \\
C\end{array}$ & $\begin{array}{l}319(42.2) \\
T\end{array}$ \\
\hline rs1800849 & 201 (53.9) & $151(40.5)$ & $21(5.6)$ & $553(74.1)$ & $193(25.9)$ \\
\hline
\end{tabular}




\begin{tabular}{|c|c|c|c|c|c|c|}
\hline SNP & Phenotype & $\begin{array}{l}\text { Mean value homozygotes } \\
\text { major allele }(95 \% \mathrm{Cl})\end{array}$ & $\begin{array}{l}\text { Difference between homozygotes } \\
\text { major allele and heterozygotes } \\
\qquad(95 \% \mathrm{Cl})\end{array}$ & $P$ value $^{\star}$ & $\begin{array}{l}\text { Difference between homozygotes } \\
\text { major and homozygotes minor } \\
\text { allele }(95 \% \mathrm{Cl})\end{array}$ & $P$ value* \\
\hline \multirow[t]{9}{*}{ rs7930460 } & BMI $\left(\mathrm{kg} / \mathrm{m}^{2}\right)$ & $26.31(25.83 ; 26.80)$ & $0.06(-0.66 ; 0.77)$ & 0.874 & $-1.45(-3.07 ; 0.18)$ & 0.081 \\
\hline & Waist circumference & $98.84(97.53 ; 100.15)$ & $0.83(-1.10 ; 2.76)$ & 0.398 & $-3.78(-8.17 ; 0.61)$ & 0.091 \\
\hline & Hip circumference & $101.65(100.78 ; 102.52)$ & $-0.05(-1.33 ; 1.23)$ & 0.938 & $-2.65(-5.56 ; 0.26)$ & 0.074 \\
\hline & Waist-to-hip ratio (WHR) & $0.97(0.96 ; 0.98)$ & $0.01(-0.00 ; 0.02)$ & 0.189 & $-0.01(-0.04 ; 0.02)$ & 0.412 \\
\hline & Fat percent (\%) & $20.40(19.79 ; 21.02)$ & $0.55(-0.35 ; 1.44)$ & 0.229 & $-0.73(-2.72 ; 1.26)$ & 0.469 \\
\hline & Total fat mass $(\mathrm{kg})$ & $16.93(16.13 ; 17.74)$ & $0.62(-0.55 ; 1.80)$ & 0.297 & $-1.60(-4.22 ; 1.01)$ & 0.228 \\
\hline & Visceral fat mass $(\mathrm{cm})$ & $7.38(7.07 ; 7.70)$ & $0.37(-0.09 ; 0.83)$ & 0.114 & $-0.51(-1.56 ; 0.54)$ & 0.339 \\
\hline & s.c. fat mass $(\mathrm{cm})$ & $2.67(2.56 ; 2.79)$ & $-0.03(-0.20 ; 0.15)$ & 0.763 & $-0.28(-0.68 ; 0.12)$ & 0.170 \\
\hline & Abdominal fat mass $(\mathrm{cm})$ & $10.06(9.71 ; 10.41)$ & $0.35(-0.17 ; 0.86)$ & 0.186 & $-0.79(-1.96 ; 0.37)$ & 0.182 \\
\hline \multirow[t]{9}{*}{ rs647126 } & BMI $\left(\mathrm{kg} / \mathrm{m}^{2}\right)$ & $25.86(25.21 ; 26.51)$ & $0.38(-0.44 ; 1.19)$ & 0.363 & $1.11(0.09 ; 2.14)$ & 0.033 \\
\hline & Waist circumference & $98.32(96.56 ; 100.09)$ & $0.63(-1.58 ; 2.85)$ & 0.574 & $2.24(-0.54 ; 5.02)$ & 0.114 \\
\hline & Hip circumference & $101.37(100.20 ; 102.54)$ & $0.07(-1.40 ; 1.54)$ & 0.924 & $0.56(-1.28 ; 2.40)$ & 0.549 \\
\hline & Waist-to-hip ratio (WHR) & $0.97(0.96 ; 0.98)$ & $0.01(-0.01 ; 0.02)$ & 0.519 & $0.02(-0.00 ; 0.03)$ & 0.062 \\
\hline & Fat percent (\%) & $20.71(19.89 ; 21.53)$ & $-0.15(-1.18 ; 0.88)$ & 0.775 & $0.00(-1.30 ; 1.30)$ & 0.995 \\
\hline & Total fat mass $(\mathrm{kg})$ & $17.03(15.95 ; 18.12)$ & $0.10(-1.26 ; 1.45)$ & 0.890 & $0.41(-1.31 ; 2.12)$ & 0.640 \\
\hline & Visceral fat mass $(\mathrm{cm})$ & $7.32(6.90 ; 7.75)$ & $0.27(-0.26 ; 0.80)$ & 0.320 & $0.37(-0.30 ; 1.03)$ & 0.276 \\
\hline & s.c. fat mass $(\mathrm{cm})$ & $2.67(2.51 ; 2.84)$ & $-0.04(-0.24 ; 0.16)$ & 0.699 & $-0.01(-0.27 ; 0.24)$ & 0.930 \\
\hline & Abdominal fat mass $(\mathrm{cm})$ & $10.00(9.53 ; 10.47)$ & $0.23(-0.36 ; 0.82)$ & 0.445 & $0.36(-0.38 ; 1.10)$ & 0.341 \\
\hline \multirow[t]{9}{*}{ rs1685356 } & BMI $\left(\mathrm{kg} / \mathrm{m}^{2}\right)$ & $25.91(25.29 ; 26.53)$ & $0.25(-0.54 ; 1.05)$ & 0.527 & $1.22(0.23 ; 2.22)$ & 0.016 \\
\hline & Waist circumference & $98.46(96.79 ; 100.14)$ & $0.30(-1.85 ; 2.45)$ & 0.784 & $2.18(-0.52 ; 4.87)$ & 0.113 \\
\hline & Hip circumference & $101.40(100.29 ; 102.51)$ & $-0.14(-1.57 ; 1.28)$ & 0.843 & $0.90(-0.88 ; 2.69)$ & 0.321 \\
\hline & Waist-to-hip ratio (WHR) & $0.97(0.96 ; 0.98)$ & $0.00(-0.01 ; 0.02)$ & 0.645 & $0.01(-0.00 ; 0.03)$ & 0.145 \\
\hline & Fat percent (\%) & 20.65 (19.86; 21.43) & $-0.09(-1.09 ; 0.92)$ & 0.866 & $0.06(-1.20 ; 1.32)$ & 0.927 \\
\hline & Total fat mass $(\mathrm{kg})$ & $16.98(15.94 ; 18.01)$ & $0.14(-1.18 ; 1.46)$ & 0.834 & $0.49(-1.17 ; 2.14)$ & 0.563 \\
\hline & Visceral fat mass $(\mathrm{cm})$ & $7.42(7.02 ; 7.82)$ & $0.09(-0.43 ; 0.61)$ & 0.735 & $0.31(-0.34 ; 0.96)$ & 0.351 \\
\hline & s.c. fat mass $(\mathrm{cm})$ & $2.63(2.48 ; 2.79)$ & $0.01(-0.19 ; 0.20)$ & 0.943 & $0.05(-0.20 ; 0.30)$ & 0.685 \\
\hline & Abdominal fat mass $(\mathrm{cm})$ & $10.05(9.61 ; 10.50)$ & $0.10(-0.48 ; 0.67)$ & 0.741 & $0.36(-0.36 ; 1.08)$ & 0.326 \\
\hline \multirow{9}{*}{ rs2632723 } & BMI $\left(\mathrm{kg} / \mathrm{m}^{2}\right)$ & 26.44 (26.00; 26.88) & $-0.62(-1.36 ; 0.13)$ & 0.103 & $-0.08(-1.87 ; 1.71)$ & 0.931 \\
\hline & Waist circumference & $99.38(98.19 ; 100.57)$ & $-1.00(-3.01 ; 1.02)$ & 0.331 & $-2.05(-6.90 ; 2.81)$ & 0.408 \\
\hline & Hip circumference & 101.47 (100.69; 102.25) & $-0.21(-1.53 ; 1.12)$ & 0.760 & $1.20(-2.00 ; 4.40)$ & 0.462 \\
\hline & Waist-to-hip ratio (WHR) & $0.98(0.97 ; 0.99)$ & $-0.01(-0.02 ; 0.01)$ & 0.217 & $-0.03(-0.06 ; 0.00)$ & 0.058 \\
\hline & Fat percent (\%) & $20.69(20.14 ; 21.24)$ & $-0.27(-1.21 ; 0.67)$ & 0.571 & $-0.50(-2.85 ; 1.86)$ & 0.679 \\
\hline & Total fat mass $(\mathrm{kg})$ & $17.20(16.48 ; 17.92)$ & $-0.33(-1.56 ; 0.89)$ & 0.593 & $-0.31(-3.38 ; 2.76)$ & 0.843 \\
\hline & Visceral fat mass $(\mathrm{cm})$ & $7.67(7.39 ; 7.96)$ & $-0.42(-0.90 ; 0.07)$ & 0.091 & $-0.64(-1.80 ; 0.53)$ & 0.284 \\
\hline & s.c. fat mass $(\mathrm{cm})$ & $2.63(2.48 ; 2.79)$ & $0.01(-0.19 ; 0.20)$ & 0.943 & $0.05(-0.20 ; 0.30)$ & 0.685 \\
\hline & Abdominal fat mass $(\mathrm{cm})$ & $10.30(9.98 ; 10.61)$ & $-0.38(-0.91 ; 0.16)$ & 0.165 & $-0.31(-1.60 ; 0.98)$ & 0.635 \\
\hline \multirow[t]{9}{*}{ rs1685354 } & BMI $\left(\mathrm{kg} / \mathrm{m}^{2}\right)$ & $26.54(26.08 ; 27.01)$ & $-0.63(-1.36 ; 0.09)$ & 0.085 & $-0.45(-2.16 ; 1.25)$ & 0.602 \\
\hline & Waist circumference & $99.51(98.25 ; 100.77)$ & $-0.97(-2.93 ; 0.99)$ & 0.332 & $-2.10(-6.72 ; 2.53)$ & 0.373 \\
\hline & Hip circumference & 101.42 (100.58; 102.25) & $0.13(-1.17 ; 1.43)$ & 0.844 & $0.76(-2.31 ; 3.82)$ & 0.626 \\
\hline & Waist-to-hip ratio (WHR) & $0.98(0.97 ; 0.99)$ & $-0.01(-0.02 ; 0.00)$ & 0.079 & $-0.03(-0.06 ; 0.00)$ & 0.077 \\
\hline & Fat percent (\%) & 20.77 (20.19; 21.35) & $-0.37(-1.27 ; 0.54)$ & 0.425 & $-0.49(-2.77 ; 1.80)$ & 0.676 \\
\hline & Total fat mass $(\mathrm{kg})$ & $17.26(16.50 ; 18.03)$ & $-0.30(-1.49 ; 0.89)$ & 0.621 & $-0.54(-3.55 ; 2.47)$ & 0.724 \\
\hline & Visceral fat mass $(\mathrm{cm})$ & 7.76 (7.46; 8.06) & $-0.52(-0.99 ;-0.05)$ & 0.030 & $-0.51(-1.61 ; 0.60)$ & 0.368 \\
\hline & s.c. fat mass $(\mathrm{cm})$ & $2.63(2.51 ; 2.74)$ & $0.03(-0.15 ; 0.21)$ & 0.727 & $0.19(-0.23 ; 0.61)$ & 0.371 \\
\hline & Abdominal fat mass $(\mathrm{cm})$ & $10.38(10.05 ; 10.72)$ & $-0.49(-1.01 ; 0.03)$ & 0.066 & $-0.31(-1.54 ; 0.91)$ & 0.615 \\
\hline
\end{tabular}




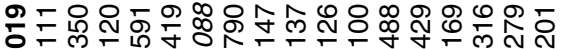

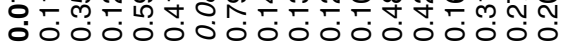
a

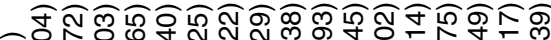
ล ㅅํํ்

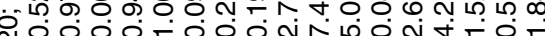
0
0
0

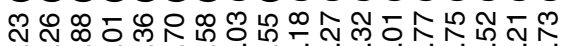
- NoO0000

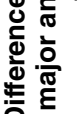

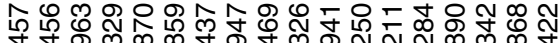
○.<smiles>[AsH2]</smiles>

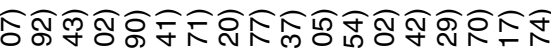
n N

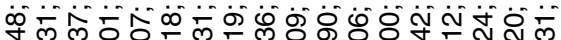
$0-1-0-1000-100$ IIIIIIIIIIIIIIIIIIIIII

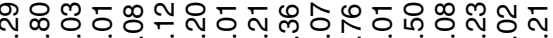

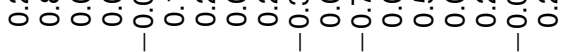

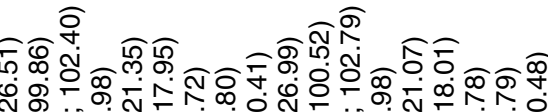

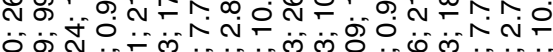

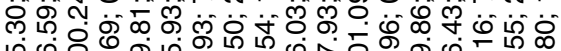
ம்

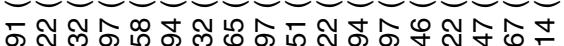

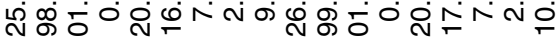

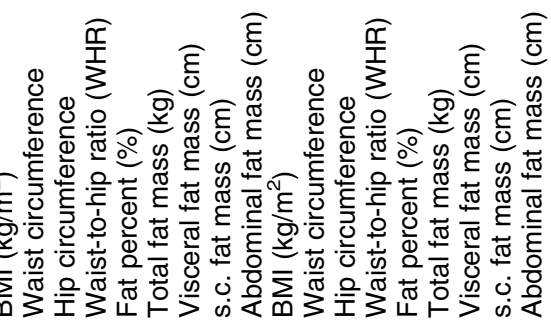

www.eje-online.org ultrasound has shown that, using a strict protocol, this is a reliable and reproducible method to assess the amount of intra-abdominal adipose tissue (30).

Our finding of a significant association between the minor allele of rs2075577 and BMI is in contrast with an association study among overweight Korean female subjects (27). In this study, single locus analyses did not lead to significant associations between this SNP and anthropometric characteristics (body weight, waist-to-hip ratio, and BMI) or measures of body composition (body fat mass, body fat percentage, fat-free mass, and body protein mass) (27). Furthermore, another study among nonHispanic and Hispanic Caucasian individuals found that the minor allele of rs 2075577 was significantly associated with an increase in dietary intake and a decrease in fat and lean mass, BMI, and percent body fat (24). However, in this paper, results were presented for females only, because no statistically significant associations between the polymorphisms considered and measures of dietary intake and body composition in males were found (24). Therefore, a sex-specific effect was suggested (24). Moreover, in accordance with our study, no significant association between rs1800849 and BMI was found in the same study (24). Two other studies among white subjects also did not find an association between this SNP and BMI $(23,26)$. Furthermore, in obese subjects, there was also a lack of association between this SNP and fat mass or other anthropometric parameters (35). On the other hand, some investigators did report an association between rs1800849 and BMI in the UK Caucasians and in the US Caucasians of Northern European origin, where the minor allele was associated with a decrease in BMI $(25,27)$. A possible explanation for these inconsistent results might be that these associations between SNPs and phenotypes are population dependent. As a result, SNPs can have variable allele frequencies and penetrance between various populations. Another explanation is that associations between a non-functional SNP and an obesity phenotype could differ between various populations.

A plausible mechanism by which polymorphisms in the $\mathrm{UCP}-3$ gene are related to BMI is that these polymorphisms decrease UCP-3 activity that leads to a decreased uncoupling of oxygen consumption from ATP production. Therefore, the dissipation of energy as heat is reduced, which, in turn, leads to an increase in body weight and BMI (7). It has been shown that a major part of the mitochondrial uncoupling is not due to inefficiency of the system, but that it is regulated by the activation of UCPs (7). UCP-3, a homolog of UCP-1 with about the same uncoupling activity, has been shown to be mainly expressed in skeletal muscle (12). Therefore, an important role for uncoupling is described to skeletal muscle and thus in the energy and substrate metabolism.

In conclusion, we have shown that genetic variations in the UCP-3 gene are associated with an increase in BMI. The effect of these SNPs might be a decreased UCP-3 activity that may lead to a decrease in uncoupling 
activity and thereby an increase in body weight and BMI. Furthermore, three SNPs showed borderline significance with several obesity-related phenotypes. Further research, using larger samples, is needed to unravel the effect of these SNPs on obesity-related phenotypes.

\section{Acknowledgements}

The authors wish to thank Drs Charlotte Onland-Moret and Sasha Zhernakova for sharing their knowledge in handling genotyping of the missing data. The authors declare that this study was not supported by funding from any source. There is no conflict of interest that would prejudice the impartiality of the paper or any other potential conflict of interest.

\section{References}

1 Kopelman PG. Obesity as a medical problem. Nature $2000 \mathbf{4 0 4}$ 635-643.

2 Zamboni M, Mazzali G, Zoico E, Harris TB, Meigs JB, Di FV, Fantin F, Bissoli L \& Bosello O. Health consequences of obesity in the elderly: a review of four unresolved questions. International Journal of Obesity 200529 1011-1029.

3 Landsberg L. A teleological view of obesity, diabetes and hypertension. Clinical and Experimental Pharmacology and Physiology $200633863-867$.

4 Warden C. Genetics of uncoupling proteins in humans. International Journal of Obesity and Related Metabolic Disorders 199923 S46-S48.

5 Bouchard C, Despres JP \& Tremblay A. Genetics of obesity and human energy metabolism. Proceedings of the Nutrition Society 199150 139-147.

6 Schrauwen P \& Hesselink M. UCP2 and UCP3 in muscle controlling body metabolism. Journal of Experimental Biology $20022052275-2285$.

7 Schrauwen P, Hoeks J \& Hesselink MK. Putative function and physiological relevance of the mitochondrial uncoupling protein3: involvement in fatty acid metabolism? Progress in Lipid Research $2006 \mathbf{4 5} 17-41$.

8 Mozo J, Emre Y, Bouillaud F, Ricquier D \& Criscuolo F. Thermoregulation: what role for UCPs in mammals and birds? Bioscience Reports 200525 227-249.

9 Klingenberg M \& Huang SG. Structure and function of the uncoupling protein from brown adipose tissue. Biochimica et Biophysic Acta 19991415 271-296.

10 Astrup A, Bulow J, Madsen J \& Christensen NJ. Contribution of BAT and skeletal muscle to thermogenesis induced by ephedrine in man. American Journal of Physiology 1985248 E507-E515.

11 Simonsen L, Stallknecht B \& Bulow J. Contribution of skeletal muscle and adipose tissue to adrenaline-induced thermogenesis in man. International Journal of Obesity and Related Metabolic Disorders 199317 (Suppl 3) S47-S51.

12 Boss O, Samec S, Paoloni-Giacobino A, Rossier C, Dulloo A, Seydoux J, Muzzin P \& Giacobino JP. Uncoupling protein-3: a new member of the mitochondrial carrier family with tissue-specific expression. FEBS Letter $1997 \mathbf{4 0 8} 39-42$.

13 Fleury C, Neverova M, Collins S, Raimbault S, Champigny O, LeviMeyrueis C, Bouillaud F, Seldin MF, Surwit RS, Ricquier D \& Warden $\mathrm{CH}$. Uncoupling protein-2: a novel gene linked to obesity and hyperinsulinemia. Nature Genetics 199715 269-272.
14 Lowell BB. Uncoupling protein-3 (UCP3): a mitochondrial carrier in search of a function. International Journal of Obesity and Related Metabolic Disorders 199923 (Suppl 6) S43-S45.

15 Bezaire V, Seifert EL \& Harper ME. Uncoupling protein-3: clues in an ongoing mitochondrial mystery. FASEB Journal 200721 312-324.

16 Saltzman E \& Roberts SB. The role of energy expenditure in energy regulation: findings from a decade of research. Nutrition Reviews $199553209-220$.

17 Dalgaard LT \& Pedersen O. Uncoupling proteins: functional characteristics and role in the pathogenesis of obesity and Type II diabetes. Diabetologia $2001 \mathbf{4 4} 946-965$.

18 Schrauwen P, Xia J, Walder K, Snitker S \& Ravussin E. A novel polymorphism in the proximal UCP3 promoter region: effect on skeletal muscle UCP3 mRNA expression and obesity in male nondiabetic Pima Indians. International Journal of Obesity and Related Metabolic Disorders 199923 1242-1245.

19 Alonso A, Marti A, Corbalan MS, Martinez-Gonzalez MA, Forga L \& Martinez JA. Association of UCP3 gene $-55 \mathrm{C}>\mathrm{T}$ polymorphism and obesity in a Spanish population. Annals of Nutrition and Metabolism 2005 49 183-188.

20 Berentzen T, Dalgaard LT, Petersen L, Pedersen O \& Sorensen TI. Interactions between physical activity and variants of the genes encoding uncoupling proteins -2 and -3 in relation to body weight changes during a 10-y follow-up. International Journal of Obesity 200529 93-99.

21 Cassell PG, Saker PJ, Huxtable SJ, Kousta E, Jackson AE, Hattersley AT, Frayling TM, Walker M, Kopelman PG, Ramachandran A, Snehelatha C, Hitman GA \& McCarthy MI. Evidence that single nucleotide polymorphism in the uncoupling protein 3 (UCP3) gene influences fat distribution in women of European and Asian origin. Diabetologia $2000 \mathbf{4 3} 1558-1564$.

22 Cha MH, Shin HD, Kim KS, Lee BH \& Yoon Y. The effects of uncoupling protein 3 haplotypes on obesity phenotypes and very low-energy diet-induced changes among overweight Korean female subjects. Metabolism 200655 578-586.

23 Dalgaard LT, Sorensen TI, Drivsholm T, Borch-Johnsen K, Andersen T, Hansen T \& Pedersen O. A prevalent polymorphism in the promoter of the UCP 3 gene and its relationship to body mass index and long term body weight change in the Danish population. Journal of Clinical Endocrinology and Metabolism 2001 86 1398-1402.

24 Damcott CM, Feingold E, Moffett SP, Barmada MM, Marshall JA, Hamman RF \& Ferrell RE. Genetic variation in uncoupling protein 3 is associated with dietary intake and body composition in females. Metabolism 200453 458-464.

25 Halsall DJ, Luan J, Saker P, Huxtable S, Farooqi IS, Keogh J, Wareham NJ \& O’Rahilly S. Uncoupling protein 3 genetic variants in human obesity: the c-55t promoter polymorphism is negatively correlated with body mass index in a UK Caucasian population. International Journal of Obesity and Related Metabolic Disorders 2001 25 472-477.

26 Herrmann SM, Wang JG, Staessen JA, Kertmen E, SchmidtPetersen K, Zidek W, Paul M \& Brand E. Uncoupling protein 1 and 3 polymorphisms are associated with waist-to-hip ratio. Journal of Molecular Medicine 200381 327-332.

27 Liu YJ, Liu PY, Long J, Lu Y, Elze L, Recker RR \& Deng HW. Linkage and association analyses of the UCP3 gene with obesity phenotypes in Caucasian families. Physiological Genomics 2005 22 197-203.

28 Otabe S, Clement K, Dina C, Pelloux V, Guy-Grand B, Froguel P \& Vasseur F. A genetic variation in the $5^{\prime}$ flanking region of the UCP3 gene is associated with body mass index in humans in interaction with physical activity. Diabetologia 200043 245-249.

29 Muller M, Grobbee DE, den Tonkelaar I, Lamberts SW \& van der Schouw YT. Endogenous sex hormones and metabolic syndrome in aging men. Journal of Clinical Endocrinology and Metabolism $2005902618-2623$.

30 Stolk RP, Wink O, Zelissen PM, Meijer R, van Gils AP \& Grobbee DE. Validity and reproducibility of ultrasonography for the measurement of intra-abdominal adipose tissue. International Journal of Obesity and Related Metabolic Disorders 200125 1346-1351. 
31 Tornaghi G, Raiteri R, Pozzato C, Rispoli A, Bramani M, Cipolat M \& Craveri A. Anthropometric or ultrasonic measurements in assessment of visceral fat? A comparative study International Journal of Obesity and Related Metabolic Disorders 199418 771-775.

32 Solanes G, Vidal-Puig A, Grujic D, Flier JS \& Lowell BB. The human uncoupling protein-3 gene. Genomic structure, chromosomal localization, and genetic basis for short and long form transcripts. Journal of Biolgical Chemistry 1997272 25433-25436.

33 Barrett JC, Fry B, Maller J \& Daly MJ. Haploview: analysis and visualization of $\mathrm{LD}$ and haplotype maps. Bioinformatics 200521 263-265.
34 Livak KJ. Allelic discrimination using fluorogenic probes and the 5' nuclease assay. Genetic Analysis 199914 143-149.

35 de Luis DA, Aller R, Izaola O, Gonzalez SM, Conde R \& Perez Castrillon JL. Lack of association of - 55CT polymorphism of UCP3 gene with fat distribution in obese patients. Annals of Nutrition and Metabolism $2007 \mathbf{5 1}$ 374-378.

Received 6 February 2008

Accepted 13 February 2008 